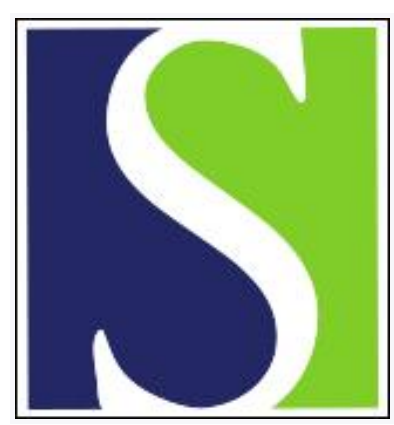

Scand J Work Environ Health 1993;19(1):43-49

https://doi.org/10.5271/sjweh.1505

Issue date: 01 Feb 1993

Shoulder tendinitis and its relation to heavy manual work and exposure to vibration.

by Stenlund B, Goldie I, Hagberg M, Hogstedt C

Affiliation: Construction Industry's Organization for Working Environment, Safety and Health, Stockholm, Sweden.

The following article refers to this text: $2022 ; 48(6): 490-497$

This article in PubMed: www.ncbi.nlm.nih.gov/pubmed/8465171

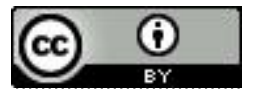




\title{
Shoulder tendinitis and its relation to heavy manual work and exposure to vibration
}

\author{
by Berndt Stenlund, MD, ${ }^{1,2}$ lan Goldie, MD, ${ }^{3}$ Mats Hagberg, MD, ${ }^{2,4}$ Christer Hogstedt, MD, $, 2,5$
}

\begin{abstract}
STENLUND B, GOLDIE I, HAGBERG M, HOGSTEDT C. Shoulder tendinitis and its relation to heavy manual work and exposure to vibration. Scand $J$ Work Environ Health 1993;19:43—9. Three categories of construction industry workers ( 54 bricklayers, 55 rockblasters, and 98 foremen) were compared in a cross-sectional study. In a structured interview they reported exposure to loads lifted, vibration, and years of manual work. They were also subjected to a clinical investigation including medical history and a detailed shoulder examination. Among the rockblasters $33 \%$ had signs of tendinitis in the left and $40 \%$ in the right shoulder. Among the bricklayers and foremen $8-17 \%$ had signs of shoulder tendinitis. In a multiple logistic regression being a rockblaster compared with being a foreman showed an odds ratio (OR) of 3.33 for left-sided and 1.71 for right-sided shoulder tendinitis. Vibration exposure yielded an OR of 1.84 and 1.66 for the left and right sides, respectively. Vibration exposure or work as a rockblaster seemed to be risk indicators for tendinitis of the shoulders.
\end{abstract}

Key terms: bricklayer, foreman, load, muscle attachment inflammation, musculoskeletal disorder, rockblaster, work-related disorders.

Several reports have indicated that stress and strain in the workplace are factors in the development of occupational shoulder disorders $(1-5)$. There are several conditions that can cause shoulder pain, but bicipital tendinitis and supraspinatus tendinitis form the great majority of soft tissue lesions in the shoulders (6).

In the construction industry many workers suffer from shoulder pain. Palpable pain is a common finding on examination in these cases. Together with pain reaction to isometric contraction of the affected muscle, this finding is interpreted as a sign of inflammation of the muscle attachment or the tendon (7).

In the present study the objective was to determine whether signs of tendinitis or muscle attachment inflammation in the shoulders was related to different work loads (eg, lifted loads), years of manual work, hours of exposure to vibration, or job title.

\section{Subjects and methods}

\section{Study subjects}

The source population, drawn from construction industry workers in the Stockholm region, constituted

I The Construction Industry's Organization for Working Environment, Safety and Health, Stockholm, Sweden.

2 Department of Occupational Health, Karolinska Hospital, Stockholm, Sweden.

3 Division of Work and Environmental Physiology, National Institute of Occupational Health, Solna, Sweden.

4 Division of Occupational Medicine, National Institute of Occupational Health, Solna, Sweden.

5 Department of Orthopedics, Karolinska Hospital, Stockholm, Sweden.

Requests for reprints to: Dr B Stenlund, Bygghälsan, Electrum/216, S-164 40 Kista, Sweden. three subgroups with a high or low degree of the exposures under study. In the Swedish construction industry, bricklayers either lay bricks or spend periods plastering; they do not cast concrete. Rockblasters drill holes both underground and on the surface. They charge dynamite and transport rocks. In tunnels they also trim the roof. Construction foremen are engineers and not manual workers, and they are rarely recruited from the manual worker group. The foremen are supervisors on the construction site; they also work in offices, which are often close to the construction place. The three groups thus represent different occupational work loads, although they have a common trade.

Representatives from these study groups were identified and randomly selected from the local union files. First, all of the 75 rockblasters in the files were included, and then 75 bricklayers in the same age groups were randomly selected. Finally, 110 foremen were randomly selected who worked with large companies so that foremen that had been exposed to manual work would be avoided.

All of the subjects were invited to participate by letter and reminded by telephone the day before the examination. Refusals were received from 19 bricklayers, 20 rockblasters, and 13 foremen, either because they did not wish to participate or because they lived in another part of the country or abroad. One bricklayer was excluded from the investigation because of language difficulties. One of the bricklayers had previously worked for 18 years as a foreman and only for the last two years as a bricklayer; he was, as a consequence, categorized as a foreman. Thus the persons under study, all male, finally comprised 54 bricklayers, 55 rockblasters, and 98 foremen.

A summary of the background variables and exposures of the subjects is presented in tables 1 and 2 . 


\section{Methods}

The investigation had the following three parts: exposure assessment, clinical examination, and radiographic examination. The results of the radiographic investigation have been published elsewhere (8).

A questionnaire was developed to record the estimated load lifted during a worklife, exposure to vibration, years of manual work, years as foreman, smoking habits, dexterity, sports activities engaging the arms, and current and previous citizenship. A specially trained nurse interviewed the participants using the questionnaire.

The exposure was analyzed on the basis of (i) sum of the loads lifted during work years, (ii) sum of the hours of exposure to vibration, (iii) years of manual work, and (iv) job title.

Load lifted was summarized on an annual basis. The participant calculated how many days he had worked per year, how many loads he had lifted per day, and their weight. All of the worktools were recorded separately. The weight of a brick and of the trowel and mortar together is approximately $3.5 \mathrm{~kg}$. Rockblasters the most frequently use jackhammers that weigh $47.2-50.7 \mathrm{~kg}$ and are lifted several times an hour. Rockblasters also load rocks of different weights, and these loads were also taken into account although their weight was not easily estimated.

Load lifted was categorized into one of the following three classes: $0-709,710-25999$, and

Table 1. Background variables and frequencies of the outcome variables in the compared groups.

\begin{tabular}{|c|c|c|c|c|c|c|}
\hline \multirow{2}{*}{ Variables } & \multicolumn{2}{|c|}{ Brickłayers } & \multicolumn{2}{|c|}{ Rock blasters } & \multicolumn{2}{|c|}{ Foremen } \\
\hline & $\mathrm{N}$ & $\%$ & $\mathrm{~N}$ & $\%$ & $\mathrm{~N}$ & $\%$ \\
\hline Right handed & 44 & 81.5 & 43 & 78.2 & 83 & 84.7 \\
\hline Left handed & 2 & 3.7 & 3 & 5.5 & 1 & 1.0 \\
\hline Ambidextrous & 8 & 14.8 & 9 & 16.4 & 14 & 14.3 \\
\hline Smokers & 24 & 44.4 & 23 & 41.8 & 28 & 28.6 \\
\hline Nonsmokers & 9 & 16.7 & 11 & 20.0 & 36 & 36.7 \\
\hline Ex-smokers & 21 & 38.9 & 21 & 38.2 & 34 & 34.7 \\
\hline Swedish citizenship & 48 & 88.9 & 50 & 90.9 & 86 & 87.8 \\
\hline Other citizenship & 6 & 11.1 & 5 & 9.1 & 12 & 12.2 \\
\hline \multicolumn{7}{|l|}{ Signs of tendinitis } \\
\hline $\begin{array}{l}\text { Left } \\
\text { Right }\end{array}$ & $\begin{array}{l}6 \\
8\end{array}$ & $\begin{array}{l}11.1 \\
14.8\end{array}$ & $\begin{array}{l}18 \\
22\end{array}$ & $\begin{array}{l}32.7 \\
40.0\end{array}$ & $\begin{array}{r}8 \\
17\end{array}$ & $\begin{array}{r}8.2 \\
17.1\end{array}$ \\
\hline \multicolumn{7}{|l|}{ Entity of tendinitis } \\
\hline $\begin{array}{l}\text { Left } \\
\text { Right }\end{array}$ & $\begin{array}{l}1 \\
1\end{array}$ & $\begin{array}{l}1.8 \\
1.8\end{array}$ & $\begin{array}{r}8 \\
13\end{array}$ & $\begin{array}{l}14.5 \\
23.6\end{array}$ & $\begin{array}{l}3 \\
9\end{array}$ & $\begin{array}{l}3.1 \\
9.2\end{array}$ \\
\hline
\end{tabular}

$>25999$ t. The limits 710 and $26000 t$ were chosen because they represented the median values for the foremen and the bricklayers and rockblasters, respectively. The value $710 \mathrm{t}$ corresponded to the lifting of $19.7 \mathrm{~kg}$ per hour, $8 \mathrm{~h}$ a day, $225 \mathrm{~d}$ a year for 20 years.

Years of manual work were categorized into $0-$ $9,10-28$, and $>28$ years, the last category representing the median value for the bricklayers and rockblasters together.

Exposure to vibration was reported in the protocol for each tool used and expressed as hours of exposure. The reported hours were then multiplied by 1,10 , and 100 , depending on the tool that had been used. These exponents correspond to the three steps of energy emission from the vibrating tools, as suggested by Gemne et al (9). The individual values were then classified into one of the following three categories: $0-8999,9000-255199$, and $>255199 \mathrm{~h}$. The limits represented the median values for the foremen and rockblasters, respectively.

The age range was $26-70$ years. The mean was 50.2 years for the bricklayers, 51.8 years for the rockblasters, and 45.8 years for the foremen (table 2). We dealt with the differences in the distribution of age, smoking habits, dexterity, and sports activities between the three groups by including all of these variables in all of the regression models.

\section{Clinical examination}

The clinical examination was carried out without knowledge of the exposure of the person being examined. The participants were examined by an orthopedic surgeon (BS) and a physiotherapist. The findings from the examination of the rotator cuff muscles were recorded, and the pain reactions were categorized into a three-point estimate as follows: grade $1=$ no pain, grade $2=$ moderate pain reaction, and grade $3=$ pronounced pain reaction.

The medical history included questions on previous injuries and diseases of the musculoskeletal system. It also contained questions on previous shoulder pain during work in different situations or at rest.

The outcome variable "signs of shoulder tendinitis" was defined as pronounced palpable pain of the muscle attachment or pronounced pain reaction to

Table 2. Background variables and exposures.

\begin{tabular}{|c|c|c|c|c|c|c|c|c|c|c|c|c|c|c|c|c|c|c|}
\hline & \multicolumn{3}{|c|}{ Age (years) } & \multicolumn{3}{|c|}{ Sports activities (h) } & \multicolumn{3}{|c|}{ Load lifted $(\mathrm{t})$} & \multicolumn{3}{|c|}{ Vibration (h) } & \multicolumn{3}{|c|}{ Vibration (weighted hours ${ }^{a}$ ) } & \multicolumn{3}{|c|}{ Years of manual work } \\
\hline & Mean & SD & Range & Mean & SD & Range & Mean & SD & Range & Mean & SD & Range & Mean & $S D$ & Range & Mean & SD & Range \\
\hline $\begin{array}{l}\text { Brick- } \\
\text { layers }\end{array}$ & 50.2 & 11.4 & $26-68$ & 2760 & 5909 & $\frac{0-}{28800}$ & 29437 & 28580 & $\begin{array}{l}114- \\
84034\end{array}$ & 1367 & 2433 & $\stackrel{0-}{9060}$ & 74705 & 154816 & $\frac{0-}{720000}$ & 30.8 & 11.2 & $2-52$ \\
\hline $\begin{array}{l}\text { Rock- } \\
\text { blasters }\end{array}$ & 51.8 & 11.6 & $33-70$ & 2173 & 6057 & $\begin{array}{l}0- \\
36000\end{array}$ & 33210 & 23572 & $\begin{array}{l}3388 \\
123082\end{array}$ & 30054 & 15499 & $\begin{array}{l}2640- \\
69030\end{array}$ & -1098 & & $\begin{array}{l}26400- \\
4379000\end{array}$ & 30.8 & 12.0 & $9-58$ \\
\hline $\begin{array}{l}\text { Fore- } \\
\text { men }\end{array}$ & 45.8 & 10.2 & $27-65$ & 1328 & 1712 & $\begin{array}{l}0- \\
9944\end{array}$ & 2261 & 3975 & $\frac{0-}{24840}$ & 1722 & 3681 & $\begin{array}{l}0- \\
26880\end{array}$ & 57031 & 169067 & $\frac{0-}{108240}$ & 4.9 & 7.1 & $0-24$ \\
\hline
\end{tabular}

a Energy weighted hours of exposure to vibration. Hours of exposure to each tool multiplied by 1,10 , or 100 corresponding to the vibration energy emitted by the tool according to Gemne et al (9). 
isometric contraction in any of the four rotator cuff muscles or the biceps muscles.

The results of subjects who had experienced pain in the shoulder during the last year and, on examination, had pronounced pain reaction to palpation or isometric contraction were analyzed in separate logistic regression models (table 3 ). We combined these variables into "a clinical entity" to demonstrate the relation between clinical tendinitis and physical work load.

\section{Interaction analysis}

The background variables of age, smoking habits, dexterity, and sports activities were fitted into the unconditional multiple logistic regression analysis in all of the models. The different work exposure variables load lifted, vibration hours, and years of manual work have been included separately in tables 3 and 4. Load lifted and vibration were fitted into the models in the categories previously described in table 2 . In table 5 the high- and low-exposure groups were compared. In one model in table 5, vibration exposure and load lifted were entered simultaneously. The job categories were bricklayer, rockblaster, and foreman. In all of the logistic regression models the results were calculated separately for the left and right sides.

The interaction analyses were performed with the

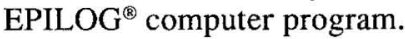

Table 3. Unconditional multiple regression of the clinical entity of tendinitis of the right and left shoulders in relation to exposure to load lifted, vibration, and years of manual work - relative risks calculated as odds ratios. $(O R=0 d d s$ ratio, $95 \% \mathrm{Cl}=95 \%$ confidence interval)

\begin{tabular}{|c|c|c|c|c|c|c|c|c|c|c|c|c|}
\hline \multirow{3}{*}{ Variables } & \multicolumn{4}{|c|}{ Model 1} & \multicolumn{4}{|c|}{ Model 2} & \multicolumn{4}{|c|}{ Model 3} \\
\hline & \multicolumn{2}{|c|}{ Right side } & \multicolumn{2}{|c|}{ Left side } & \multicolumn{2}{|c|}{ Right side } & \multicolumn{2}{|c|}{ Left side } & \multicolumn{2}{|c|}{ Right side } & \multicolumn{2}{|c|}{ Left side } \\
\hline & OR & $95 \% \mathrm{Cl}$ & OR & $95 \% \mathrm{Cl}$ & OR & $95 \% \mathrm{Cl}$ & OR & $95 \% \mathrm{Cl}$ & OR & $95 \% \mathrm{Cl}$ & OR & $95 \% \mathrm{Cl}$ \\
\hline $\begin{array}{l}\text { Lifted load: } 0-709 \text {, } \\
710-25999, \\
>25999 t\end{array}$ & 1.04 & $0.50-2.18$ & 1.55 & $0.58-4.12$ & . & . & . & . & . & . & . & . \\
\hline $\begin{array}{l}\text { Vibration: } 0-8999, \\
9000-255199, \\
>255199 \mathrm{~h}^{\mathrm{b}}\end{array}$ & . & . & . & . & 1.86 & $1.00-3.44$ & 2.49 & $1.06-5.87$ & . & . & . & . \\
\hline $\begin{array}{l}\text { Manual work: } 0-9 \text {, } \\
10-28,>28 \text { years } \\
\text { of manual work }\end{array}$ & . & . & . & . & . & . & . & . & 0.96 & $0.51-1.83$ & 2.31 & $.85-6.28$ \\
\hline
\end{tabular}

a Adjustment made for age, dexterity, smoking, and sports activities in all of the models, as in table 4.

b Weighted hours, that is, hours of exposure to each tool multiplied by 1 , or 10 , or 100 corresponding to the vibration energy emitted by the tool according to Gemne et al (9).

Table 4. Unconditional multiple regression of signs of shoulder tendinitis of the left and right shoulder in relation to exposure to loads lifted, vibration, and years of manual work - relative risks calculated as odds ratios controlled for hours of participation in sports. (OR = odds ratio, $95 \% \mathrm{Cl}=95 \%$ confidence interval)

\begin{tabular}{|c|c|c|c|c|c|c|c|c|c|c|c|c|}
\hline \multirow{3}{*}{ Variables } & \multicolumn{4}{|c|}{ Model 1} & \multicolumn{4}{|c|}{ Model 2} & \multicolumn{4}{|c|}{ Model 3} \\
\hline & \multicolumn{2}{|c|}{ Right side } & \multicolumn{2}{|c|}{ Left side } & \multicolumn{2}{|c|}{ Right side } & \multicolumn{2}{|c|}{ Left side } & \multicolumn{2}{|c|}{ Right side } & \multicolumn{2}{|c|}{ Left side } \\
\hline & OR & $95 \% \mathrm{Cl}$ & OR & $95 \% \mathrm{Cl}$ & OR & $95 \% \mathrm{Cl}$ & OR & $95 \% \mathrm{Cl}$ & OR & $95 \% \mathrm{Cl}$ & OR & $95 \% \mathrm{Cl}$ \\
\hline
\end{tabular}

$\begin{array}{lllllllllllllllll}\text { Stratum constant } & 0.004 & 0.001-0.032 & 0.005 & 0.001-0.036 & 0.000 & 0.000-0.017 & 0.005 & 0.001 & 0.032 & 0.004 & 0.001-0.029 & 0.007 & 0.001 & 0.042\end{array}$

Age: $25-39$,

$40-55,56-70$

years old

$2.92 \quad 1.65-5.18 \quad 2.12 \quad 1.12-4.00 \quad 2.75 \quad 1.59-4.77 \quad 2.34 \quad 1.26-4.35 \quad 2.80 \quad 1.55-5.06 \quad 1.85 \quad 1.00-3.65$

Dexterity: right-

handed versus

left-handed and
ambidextrous

Smoking: non-

smokers versus

ex-and current

smokers

2.20

$0.78-6.18 \quad 0.46$

$0.14-1.54 \quad 2.27$

$0.80-6.38 \quad 0.47$

$0.14-1.54 \quad 2.21$

$0.78-6.23 \quad 0.45$

$0.13-1.50$

Lifted load: 0 -

$709,710-25999$.

$>25999 \mathrm{t}$

$\begin{array}{lllll}3.37 & 1.21-9.43 & 2.15 & 0.69-6.73 & 3.06\end{array}$

$1.09-8.62 \quad 2.15$

$0.68-6.76 \quad 3.28$

$1.17-9.21 \quad 2.03 \quad 0.65-6.41$

$1.02 \quad 0.59-1.76 \quad 1.81 \quad 0.95-3.44$

$0-8999$.

255199 ,

$>255199 \mathrm{~h}^{\mathrm{b}}$

$1.66 \quad 1.06-2.61 \quad 1.84 \quad 1.10-3.07$

Manual work:

$0-9,10-28$

$>28$ years of

manual work

a Life hours of sports activities that included movements of the arms were entered in the regression analysis on an hour per hour basis.

b Weighted hours, that is hours of exposure to each tool multiplied by 1,10 , or 100 corresponding to the vibration energy emitted by the tool according to Gemne et al (9). 
Table 5. Separate and combined analysis of lifted load and vibration with the highest exposure compared with the lowest. Unconditional multiple regression of signs of shoulder tendinitis of the left and right shoulder in relation to exposure to loads lifted and vibration. ${ }^{a}$ (OR = odds ratio, $95 \% \mathrm{Cl}=95 \%$ confidence interval)

\begin{tabular}{|c|c|c|c|c|c|c|c|c|c|c|c|c|}
\hline \multirow{3}{*}{ Variables } & \multicolumn{4}{|c|}{ Model 1} & \multicolumn{4}{|c|}{ Model 2} & \multicolumn{4}{|c|}{ Model 3} \\
\hline & \multicolumn{2}{|c|}{ Right side } & \multicolumn{2}{|c|}{ Left side } & \multicolumn{2}{|c|}{ Right side } & \multicolumn{2}{|c|}{ Left side } & \multicolumn{2}{|c|}{ Right side } & \multicolumn{2}{|c|}{ Left side } \\
\hline & OR & $95 \% \mathrm{Cl}$ & OR & $95 \% \mathrm{Cl}$ & OR & $95 \% \mathrm{Cl}$ & OR & $95 \% \mathrm{Cl}$ & OR & $95 \% \mathrm{Cl}$ & OR & $95 \% \mathrm{Cl}$ \\
\hline $\begin{array}{l}\text { Lifted load: } 0-709 \\
\text { versus }>25999 \mathrm{t}\end{array}$ & 1.09 & $0.27-4.36$ & 2.92 & $0.51-16.89$ & & . & . & . & 0.87 & $0.13-5.88$ & 1.60 & $19-13.47$ \\
\hline $\begin{array}{l}\text { Vibration: } 0-8999 \\
\text { versus }>255199 \mathrm{~h}^{\mathrm{b}}\end{array}$ & . & . & . & . & 2.42 & $0.93-6.30$ & 3.04 & $0.98-9.40$ & 1.87 & $0.39-8.95$ & 2.64 & $56-12.53$ \\
\hline
\end{tabular}

a Adjustment made for age, dexterity, smoking, and sports activities in all of the models, as in table 4.

- Weighted hours, that is, hours of exposure to each tool multiplied by 1,10 , or 100 corresponding to the vibration energy emitted by the tool according to Gemne et al (9).

\section{Results}

Signs of tendinitis of the shoulder were defined as pronounced palpable pain of the muscle attachment or pronounced pain reaction to isometric contraction in any of the four rotator cuff muscles and the biceps muscles. Among the rockblasters $40 \%$ had signs of tendinitis in the right shoulder, and 33\% had signs of tendinitis in the left shoulder, whereas among the foremen and bricklayers only $8-15 \%$ had positive signs of tendinitis (table 1). The bricklayers had lower frequencies of signs of tendinitis than the foremen.

In the unconditional multiple logistic regression analyses for vibration exposure, the odds ratio for signs of tendinitis was 1.66 for the right side and 1.84 for the left side (table 4). Load lifted during worklife and the variable years of manual work yielded odds ratios close to 1.0 for the right side, but for the left side the load lifted yielded an odds ratio of 1.81 . Years of manual work yielded an odds ratio of 1.87 for the left side, and job title an odds ratio of 2.26; the $95 \%$ confidence interval $(95 \% \mathrm{CI})$ for job title included 1.0, indicating uncertainty (table 4).

Work as a rockblaster in comparison with work as a foreman yielded a relative risk of $3.33(95 \% \mathrm{CI}$ $1.21-9.15)$ for signs of shoulder tendinitis on the left side and $1.71(95 \%$ CI $0.71-4.17)$ for the right side. Work as a bricklayer or rockblaster in comparison with work as a foreman yielded an odds ratio of $2.10(95 \%$ CI $0.84-5.24)$ for the left side and $1.00(95 \% \mathrm{CI} 0.47-2.16)$ for the right side. Work as a bricklayer yielded an odds ratio of $0.44(95 \%$ CI $0.16-1.25$ ) for signs of shoulder tendinitis on the right side, but for the left side the coefficient estimates did not converge because of too few cases. Adjustments were made for age, dexterity, smoking, and sports activities.

The entity of tendinitis (ie, the combined variable of symptoms of pain in the shoulder during the last year and either pronounced palpable pain or pronounced pain reaction to isometric contraction) was also more common among the rockblasters than among the foremen and bricklayers (table 1).

Vibration yielded even higher odds ratios. The risk estimate was 2.49 for the left side and 1.86 for the right side. For load lifted, years of manual work, and job title the estimated odds ratios were not significant, as indicated by the confidence intervals (table 3).

The findings presented in tables 4 and 5 indicated the possibility of a exposure-response relationship in that a comparison of high-vibration exposure with low-vibration exposure yielded higher odds ratios (table 5) than the comparison of three classes, as in table 4 . In table 5 a comparison was demonstrated between low exposure and high exposure without the medium exposure.

\section{Discussion}

Exposure to vibrating tools such as jackhammers for long periods of time was demonstrated to raise the relative risk for tendinitis of the shoulder muscles. In some models job title, loads lifted, or years of manual work yielded increased risks for tendinitis of the shoulders, but, according to the $95 \%$ confidence intervals, the estimates were uncertain.

\section{Selection bias}

A selection bias that may have influenced the outcome is the possibility that the issue under study, tendinitis of the shoulder, makes it impossible to work as a bricklayer or rockblaster but does not influence work as a foreman to an equivalent degree. Such selection would lead to an underestimation of the relative risk, since there would be fewer bricklayers and rockblasters with tendinitis of the shoulder available for the study. There were six foremen who had changed jobs from heavy manual work to foreman but only one of them had changed jobs because of a musculoskeletal disorder of the shoulder.

\section{Misclassification of exposure}

Nondifferential misclassification diminishes any truly increased risk (10). In our study, nondifferential misclassification might have been introduced by the use of subjective assessments of exposure. Kilbom et al (11) demonstrated that $20 \%$ of self-reported lifts did not occur in the workplace and that only $10 \%$ of the workers reported correct weights and frequencies of 
material handled. In the present study, the use of many different exposure variables was one way of minimizing the subjective influence on estimations of occupational stress. Another was to categorize the exposure parameters in broad classes so that the exact values played a less prominent role.

The reported mean hours of vibration exposure for rockblasters were almost 22 times larger than for bricklayers and 17.5 times larger than for foremen. After multiplication by 1,10 , or 100 to produce energy-weighted hours of vibration exposure, the rockblasters' values were 14.7 times larger than the bricklayers' and 19.3 times larger than the foremen's. This finding indicates that the foremen reported many more hours of vibration exposure with tools emitting low-energy vibration (table 2). Thus there was no indication that the transformation into energy-weighted hours of vibration overestimated the vibration exposure.

Age can result in a differential misclassification of exposure assessment since older people in general may have more difficulties in recalling exposure than younger people. This phenomenon would also diminish a truly increased risk.

\section{Misclassification of outcome}

The pain reactions to palpation and isometric contraction were classified into one of three grades. In the calculations only grade 3 , pronounced pain reaction, was classified as a positive sign of tendinitis or muscle attachment inflammation. The difference between grades 2 and 3 is relatively distinct. In order to minimize the risk of misclassification (eg, by altering criteria by time) each grading of any uncertainty was made as a consensus judgment by one of the authors (BS) and a physiotherapist.

The demonstrated signs of tendinitis, palpable pain, and pain reaction to isometric contraction, are not the exact criteria used for the clinical diagnosis of tendinitis or muscle attachment inflammation. The clinical entity used in our investigation included symptoms of pain during the last year that could have originated from structures other than the tendons or the muscle attachments in the shoulders. From clinical experience we know that tendinitis and muscle attachment inflammation are the most common disorders in the shoulders. Therefore it is highly probable that our "clinical entity" was closely related to clinical tendinitis. In other words persons who have experienced pain in their shoulder during the last year and on examination have pronounced pain reaction to palpation or isometric contraction have probably had a disorder in the identified muscle attachment or tendon that, in clinical practice, would have been classified as inflammation or tendinitis.

In clinical practice patients call on a physician because of pain, and the clinical examination verifies the diagnosis tendinitis. In that situation the number of tendinitis patients does not reflect a true preva- lence ratio of tendinitis in the population since there are persons with tendinitis who, for various reasons, will not see a physician for their symptoms. The situation is that of selection bias. In the present study no such bias was introduced as the study had a crosssectional design.

\section{Confounding}

Age, smoking habits, dexterity, and sports activities, all of which are possible confounders, were included in all of the multiple logistic regression models. Age was entered as three classes in the logistic regression analysis, and it yielded odds ratios of $2-3$ in most of the models for the right side and odds ratios of $1-2.4$ for the left side.

Smoking also seemed to have an influence on tendinitis of the shoulder although, in most cases, the 95\% confidence intervals indicated uncertainty. Among the bricklayers $83 \%$ were smokers or exsmokers, among the rockblasters $80 \%$ were smokers or ex-smokers, whereas among the foremen $63 \%$ were smokers or ex-smokers (table 1). Thus there was a co-variation between smoking and heavy work.

Sports activities were entered in all of the models as hours of sports activities without classification. Sports activities, classified as low-, medium-, and high-level, will be analyzed in relation to tendinitis of the shoulder and osteoarthrosis of the acromioclavicular joint, and the results will be reported in another publication.

The three groups of subjects were chosen initially to contrast heavy manual work to light work and exposure to vibration to no such exposure in the same study base of construction trade employees. Bricklayers work with equal loads on each hand, and rockblasters also lift their tools and material with both hands. Thus dexterity may have little significance in these situations, but it was treated as a confounder in the interaction analyses since there were more lefthanded and ambidextrous workers among the bricklayers and rockblasters. Tendinitis was more common on the right side in all of the groups (table 1). In all of the interaction analyses however the left side yielded higher odds ratios than the right side for all of the work-related variables. One reason for this finding might be that the right hand is used more often in vigorous activities, even outside work, and that the rockblasters are an exception because they have to use both hands simultaneously in vigorous activities at work.

Vibration exposure seemed to be a risk indicator, but, since vibration exposure is indivisible from static load and heavy lifting in the present data, all three are possible risk indicators or can be looked upon as confounders. In the analysis in table 5, lifted load was entered simultaneously with vibration exposure. Vibration still rendered increased odds ratios (OR 1.87 and 2.64), a finding which supports the fact that vibration without the influence of lifted load still acts 
as an indicator of risk for tendinitis of the shoulders. The subjects who had reported the highest exposure to vibration were the rockblasters. Rockblasters also make heavy lifts several times a day as opposed to bricklayers and foremen. Vibration exposure is thus indivisible from exposure to heavy lifts. The collected data did not separate heavy lifts from light ones, and the question of whether vibration is a true risk indicator or whether there is another risk factor involved that is strongly linked to vibration exposure, like heavy lifts, remains unanswered.

\section{Mechanism of injury}

The mechanism of injury to a tendon or a muscle attachment in the shoulder includes several factors. The arterial pattern of the rotator cuff has been mapped by Moseley \& Goldie (12), and they found no evidence that the "critical zone" for ruptures and calcified deposits was much less vascularized. During raised intramuscular pressure there might however be a lowered blood flow and a possibility for injury (13). Another obvious injurious factor is momentary overload (14). Yet another possible factor is overload as a result of enhanced muscle contraction by the tonic vibration reflex $(15,16)$.

The our finding that rockblasters had high relative risks for tendinitis could be explained by all of these theoretical factors. It is obvious that working as a rockblaster involves exposure to vibration. Vibration exposure from handheld tools also implies exposure to static load, which has been demonstrated to raise internal muscle pressure (13). Rockblasters lift heavy burdens like jackhammers and rocks of different weights. The lifting of heavy weights can cause ruptures of the tendons or muscle attachments (14).

Bricklayers were found to have a low prevalence of clinical entity, $1.8 \%$, which was the same prevalence figure that Herberts et al (2) and Bergenudd et al (17) reported. This prevalence is low even though bricklayers lift a mean of $29437 \mathrm{t}$ during their worklife, and it indicates that repetitive loading with small weights is not hazardous to the shoulder muscles, maybe because there is such a low amount of static load in the work of a bricklayer. It is highly unlikely that bricklayers leave work because of shoulder tendinitis to a higher extent than rockblasters since both jobs are considered to be two of the hardest in the construction industry. Therefore selection bias in the present study was unlikely.

\section{External validity}

Signs of tendinitis in the shoulders (eg, palpable pain) were found in $40 \%$ of the right shoulders and $33 \%$ of the left shoulders of the rockblasters. The same signs of tendinitis have been investigated by Bergenudd et al (17), and they found that only $2 \%$ of a group of healthy subjects had palpable pain in the rotator cuff or biceps muscles of the shoulders.
Herberts et al (2) examined welders and found a prevalence of $16-18 \%$ for tendinitis of the shoulders in that group. The authors drew attention to the arm positioning, namely, overhead work, as an important risk factor for shoulder tendinitis. Luopajärvi et al (4) investigated assembly workers and found an increased prevalence of shoulder tendinitis. Static load and overhead work were pointed out as risk factors for tendinitis of the shoulders.

There have been several studies that have demonstrated a relation between heavy work and shoulder pain, but there are few studies in which quantified exposure variables within the occupation have been analyzed $(1,3,5)$. The results of our study support those of previous studies in the assumption that heavy work is a risk indicator for shoulder tendinitis, but we also found that vibration exposure could to be a true risk indicator. The risk for shoulder tendinitis on the right side increases by 1.66 for each step between the three classes of vibration exposure (0-8999, 9000-255 199, >255 199 exposure hours), and for the left side the corresponding increase is 1.84 .

\section{Concluding remarks}

Exposure to vibration or work as a rockblaster seems to be a risk indicator for muscle attachment inflammation or tendinitis in the shoulders. However, since vibration exposure from handheld vibrating tools is interlinked with exposure to static load, and for rockblasters it is also interlinked with exposure to heavy lifts, vibration exposure is possibly an indicator for either of these risk factors. Work as a bricklayer indicated a low risk for shoulder tendinitis. Years of manual work and the sum of load lifted during one's worklife did not seem to be risk indicators for tendinitis of the shoulders.

Further efforts should be made to release humans from acting as a stand for tools that are heavy and transmit vibration to the arms and the rest of the body. The tools should be constructed so that they contain the stand needed for their operation. The stand could be a small caterpillar or some sort of tripod. In this way exposure to vibration and heavy static load could be avoided.

\section{Acknowledgments}

This study was supported by grants from the Swedish Labour Market Insurance Company, Arbetsmarknadens Försäkrings AB, and the Research Foundation of Bygghälsan.

We want to thank Ms B Olofsson and Mr S Norlander for their help with the data collection.

\section{References}

1. Hagberg M, Wegman DH. Prevalence rates and odds ratios of shoulder neck diseases in different occupa- 
tional groups. Br J Ind Med 1987;44(9):602-10.

2. Herberts P, Kadefors R, Andersson G, Petersén I. Shoulder pain in industry: an epidemiological study on welders. Acta Orthop Scand 1981;52:299-306.

3. Hult L. Cervical, dorsal and lumbar spinal syndromes. Acta Orthop Scand Suppl 1954;17:100p.

4. Luopajärvi T, Kuorinka I, Virolainen M, Holmberg M. Prevalence of tenosynovitis and other injuries of the upper extremities in repetitive work. Scand J Work Environ Health 1979;5 suppl 3:48-55.

5. Ohlsson K, Attewell R, Skerfving S. Self-reported symptoms in the neck and upper limbs of female assembly workers: impact of length of employment, work pace, and selection. Scand J Work Environ Health $1989 ; 15: 75-80$.

6. Waris P. Occupational cervicobrachial syndromes: a review. Scand J Work Environ Health 1979;5 suppl $3: 3-14$.

7. Waris P, Kuorinka I, Kurppa K, Luopajärvi T, Virolainen M, Pesonen K, Epidemiologic screening of occupational neck and upper limb disorders: methods and criteria. Scand J Work Environ Health 1979;5 suppl 3: $25-38$.

8. Stenlund B, Goldie I, Hagberg M, Hogsted C, Marions O. Radiographic osteoarthrosis in the acromioclavicular joint resulting from exposure to heavy manual work and vibration. $\mathrm{Br} J$ Ind Med. In press.

9. Gemne G, Ekenvall L, Hansson J-E, Lidström I-M. Skadlig inverkan av hand-arm-vibrationer: en försäkringsmedicinsk bedömningsmodell [A medico-legal model for the evaluation of harmful influence from hand-arm vibration]. Stockholm: Arbetarskyddsverket,
1986. (Arbete och hälsa; no 1986:2.)

10. Flegal KM, Brownie C, Haas JD. The effects of exposure misclassification on estimates of the relative risk. Am J Epidemiol 1986;123:736-51.

11. Kilbom $\AA$, Liew M, Lagerlöf E, Broberg E. Ergonomisk studie av muskuloskeletala sjukdomar anmälda som arbetsskador [An ergonomic study of notified cases of occupational musculoskeletal disease]. Stockholm: Arbetarskyddsverket, 1984. (Arbete och hälsa; no 1984:45.)

12. Moseley H F, Goldie I. The arterial pattern of the rotator cuff of the shoulder. J Bone Jt Surg 1963;45B:780-9.

13. Järvholm U, Styf J, Suurkula M, Herberts P. Intramuscular pressure and muscle blood flow in supraspinatus. Eur J Appl Physiol 1988;58:219—24.

14. Zernicke RF, Garhammer J, Jobe FW. Human patellar-tendon rupture. J Bone Jt Surg 1977;59-A:17983.

15. Bongiovanni LG, Hagbart KE. Tonic vibration reflexes elicited during fatigue from maximal voluntary contraction in man. J Physiol (London) 1990;423:1-14.

16. Rohmert W, Wos H, Norlander S, Helbig R. Effects of vibration on arm and muscles in three body postures. Eur J Appl Physiol 1989;59(4):243-8.

17. Bergenudd $\mathrm{H}$, Lindgärde $\mathrm{F}$, Nilsson $\mathrm{B}$, Pettersson $\mathrm{C}$. Shoulder pain in middle age. Clin Orthop 1988;231: 234-8.

Received for publication: 29 April 1992 